\title{
Política de leitura na Educação Infantil: da gestão ao leitor
}

\section{Reading policy in early childhood education: from management to the reader}

Marly Amarilha* ${ }^{* 1}$

Sayonara Fernandes da Silva**

*Professora Titular da Universidade Federal do Rio Grande do Norte - UFRN, Centro de Educação, Departamento de Fundamentos e Políticas da Educação, Natal, RN, Brasil. marlyamarilha@yahoo.com.br

**Doutoranda em Educação da Universidade Federal do Rio Grande do Norte - UFRN; Professora da Secretaria Municipal de Educação - SME; Professora da Secretaria Estadual da Educação e da Cultura SEEC; Natal, RN, Brasil. sayonara.sayonara@yahoo.com.br

\begin{abstract}
Resumo
Este artigo tem como objetivo investigar política de implantação, na Educação Infantil, do Programa Nacional Biblioteca da Escola - PNBE. Adotando uma abordagem quanti-qualitativa, analisa-se o percurso do acervo de livros da gestão até o leitor. O corpus é constituído de 21 Centros Municipais de Educação Infantil da Rede de Ensino de Natal-RN, Brasil, de um universo de 69. Dados derivam de entrevista semiestruturada com gestores da Secretaria Municipal de Educação. Resultados indicam que a política descentralizadora de gestão do programa descompromete os atores de responsabilidade em sua implantação. Assim, a despeito de grande investimento, leitores, em rito iniciático, passam fome de leitura, ilhados por caixas de tesouros fechadas.

Palavras-chave: política de leitura, gestão, educação infantil.
\end{abstract}

\footnotetext{
${ }^{1}$ Ph.D. em Literatura - University of London
} 


\title{
pro.p̣osıções
}

\section{Abstract}

This article investigates the National Program Library in the School (Programa Nacional Biblioteca da Escola-PNBE) policy in early childhood education. It analyses the journey of the collection of books from the managers to the reader adopting a quantitative-qualitative approach. The corpus encompasses 21 Municipal Centers of Early Childhood Education Network out of 69 units, located in Natal - Rio Grande do Norte, Brazil. Data comes from semi-structured interviews with administrators of the Municipal Secretary of Education. Results indicate that decentralizing management of the Program releases the agents from their responsibilities' towards the implementation of the policy. Therefore, despite great investments, the readers in initial processes of reading have their needs neglected, surrounded by closed treasure boxes.

Keywords: reading policy, management, early childhood education.
\end{abstract}

Silencioso: quer fechado ou aberto, inclusive o que grita dentro; anônimo:só expõe o lombo, posto na estante, que apaga em pardo todos os lombos; modesto: só se abre se alguém o abre...

João Cabral de Melo Neto

Os versos de João Cabral de Melo Neto, em epígrafe, convocam-nos a pensar sobre a necessidade de abrirmos os livros às novas gerações. Livros são criaturas silenciosas, modestas como quer a personificação do poeta, entretanto, generosos desde que alguém os abra.

Ao refletimos sobre o caráter colaborativo presente nas relações que o livro provoca (sem alguém que o abra ele permanecerá silencioso), entendemos que uma rede sensível é lançada a muitos profissionais a quem é dada a possibilidade de estabelecer vínculos e responsabilidades, quando se trata das políticas públicas voltadas para a leitura neste país.

A motivação para pesquisarmos O Programa Nacional Biblioteca da Escola - PNBE decorre do entendimento de que ler literatura é um direito, e o programa é um possível caminho em que esse direito pode se realizar. Nesse sentido, procuramos entender o PNBE sob a ótica de sua implementação na Educação Infantil de Natal-RN, Brasil. Este artigo é um 


\section{pro.posıções}

recorte da pesquisa de mestrado "O Programa Nacional Biblioteca da Escola - PNBE: da gestão ao leitor na Educação Infantil de Natal-RN" (Silva, 2015), em que destacamos as vozes dos atores, em posições de gestão, envolvidos no processo de implementação do PNBE na Educação Infantil em Natal. O limite da pesquisa abrange o período de 2008 a 2012.

\section{Pelo direito à literatura}

A leitura é um direito de todos. Mas esse direito não está assegurado a todas as crianças brasileiras. Nas últimas décadas, a literatura brasileira para a infância tem apresentado produções de qualidade com os mais variados enfoques e temas, em paralelo à literatura geral. Entretanto, para que essa produção chegue aos leitores, a instituição de uma política de formação de leitores é condição básica; assim, ao se promover a democratização da leitura e da literatura entre crianças das escolas brasileiras, pode-se reverter a tendência histórica do acesso aos livros e à leitura como bens culturais disponíveis apenas a parcelas da população.

A promoção da leitura literária por meio de política pública é, sem dúvida, a oportunidade de superar as lacunas da formação do leitor no Brasil. Entendemos que tal política deva envolver ações sobre o financiamento, as responsabilidades nas instituições de ensino, do gestor, do aprendiz, do educador, sua formação, e o compromisso de todos os segmentos sociais com a prática de educar, incluindo os familiares e a escola. Esperamos que essa promoção fomente uma visão crítica do mundo e permita ao sujeito inserção social para a cidadania, para o exercício de seus direitos e deveres.

Nessa perspectiva, Antonio Candido (2012), ao aproximar direitos humanos e literatura, afirma que

a literatura corresponde a uma necessidade universal que deve ser satisfeita sob pena de mutilar a personalidade, porque pelo fato de dar forma aos sentimentos e à visão do mundo ela nos organiza, nos liberta do caos e, portanto nos humaniza. Negar a fruição da literatura é mutilar a nossa humanidade. (pp. 17-40)

A reflexão do autor assinala a natureza fundamental da literatura na constituição da identidade humana. Muitas pessoas passam toda uma vida sem nunca ter contato com a literatura, sem viver a experiência da ficção, sem o encantamento e o encontro com os 


\section{pro.posições}

personagens que povoam os enredos e que instigam o pensamento criativo e a imaginação. É justo que isso ocorra, quando entendemos o que estão perdendo?

O interesse pela investigação do tema, - o Programa Nacional Biblioteca da Escola PNBE -, pelo viés da gestão de políticas públicas e da formação do leitor infantil está embasado no pressuposto de que a linguagem e os enredos literários proporcionam à criança a possibilidade de adquirir autoestima, identidade cultural, independência e capacidade para lidar com o mundo à sua volta (Tuttle \& Paquette, 1991).

Nesse contexto, investigamos como o Programa Nacional Biblioteca da Escola está sendo implementado em Natal-RN como política de formação de leitores da Educação Infantil, considerando que, para muitas crianças, é somente no sistema escolar que têm a possibilidade de acesso à literatura.

A literatura é porta de acesso à linguagem pelo jogo imaginativo no uso das palavras, é um meio eficiente de enriquecimento e desenvolvimento da personalidade, da vida em sociedade e do senso crítico. Sem contar que a infância é a fase mais propícia para se aprender a gostar de ler, pois é nesse período da vida que estão abertas todas as possibilidades para o aprendizado, sobretudo a ludicidade que o texto literário apresenta.

Ao ler literatura, possibilita-se a construção de subjetividades, e ela pode representar para cada criança as mais diferentes experiências. Quanto mais o professor se envolver com os livros e as histórias, mais ele poderá contribuir com a formação da criança leitora, sem contar que as crianças precisam ser fluentes na linguagem. As dificuldades nessa área podem desestimular e comprometer uma vida escolar e social bem-sucedida. A literatura se mostra como caminho estimulante para se adentrar a sociedade, pois favorece um verdadeiro ensaio geral para a vida.

No que concerne às políticas públicas, ainda existe no Brasil uma larga distância entre o real e o desejo da igualdade de acesso à leitura e aos bens culturais. Entretanto, grande investimento do governo federal tem sido feito na aquisição e na distribuição de livros para todas as unidades de ensino públicas do País, seja da zona urbana ou da zona rural, por meio do Programa Nacional Biblioteca da Escola - PNBE. Desde 2008, quando a Educação Infantil foi incluída no programa, até o ano de 2014, foram investidos $\mathrm{R} \$ 96.009 .536,40$ (noventa e seis milhões, nove mil, quinhentos e trinta e seis reais e quarenta centavos) na aquisição de livros para esse nível de educação. 


\section{pro.posıções}

Em tempos modernos, a palavra politica ganha novos significados com autores como Castro e França (2012), Rua (2009), Secchi (2010) na medida em que o termo é utilizado para se referir à dimensão coletiva, geralmente se voltando para a análise de elementos, como a relação entre indivíduo e administração pública, entre as estruturas da coletividade e a dos indivíduos. Nessa lógica, a política, na atualidade, deve ser compreendida como atividade ou conjunto de atividades que tem como termo de referência o Estado.

As políticas públicas são intervenções do poder público, planejadas com a finalidade de resolver demandas socialmente relevantes. Essas demandas são interpretadas por aqueles que ocupam o poder, influenciadas por uma agenda provocada pela sociedade civil por meio da pressão e da mobilização social, que tanto podem influir nas políticas já em vigor, como participar para apresentar alternativas, visando atender aos interesses da maioria da população.

É ingênuo pensar que os programas e as políticas criados para minimizar as condições de desigualdades sociais são ações benevolentes do governo como reconhecimento da obrigatoriedade de cumprir seu papel na construção de propostas e na mediação de conflitos. Ao contrário, todas são conquistas advindas da sociedade em constante luta e reivindicação por melhor qualidade de vida.

Neste estudo, a gestão das políticas públicas é compreendida como interação entre Estado e sociedade, serviço público e sociedade, visando ao fortalecimento da cidadania. Essas políticas estão explicitadas, sistematizadas ou formuladas em documentos (leis, programas, linhas de financiamentos) que norteiam ações que envolvem a aplicação de recursos públicos.

Podemos dizer que as políticas públicas traduzem, em seus processos de formulação, implantação e, sobretudo, nos resultados, formas de exercício do poder político, envolvendo a distribuição e redistribuição de poder, a diminuição do conflito social nos processos de decisão, de divisão de custos e benefícios sociais.

Assim, toda política pública possui uma intencionalidade, e para compreendê-la é preciso conhecer a identidade de seus formuladores e o contexto (político, social, econômico e histórico) em que foi elaborada. Por isso, por mais gratuitas que pareçam ser, as políticas públicas agregam interesses dos seus formuladores com o objetivo de responder às demandas; ampliar e efetivar direitos de cidadania; promover o desenvolvimento; gerar renda; e regular conflitos. 


\section{pro.posıções}

Considerando o contexto histórico, político e econômico que norteia as ações governamentais a partir das reformas de financiamento da educação ocorridas em 1996, o processo de descentralização financeira, desenvolvido pelo Governo Federal, possibilita a autonomia e propõe novos desafios à Educação Básica, em termos da melhoria da qualidade dos serviços e da formação dos atores que atuam diretamente no âmbito das escolas.

Nesse quadro de referência, para Castro e França (2007),

a descentralização da gestão apresentava-se como estratégia fundamental para garantir a melhoria da qualidade da escola, aumentar sua eficiência, sua eficácia e sua produtividade. Mas, para esse alcance, fazia-se necessária a substituição dos modelos centralizados de gestão por estruturas descentralizadas que criassem espaços para colegiados e para a participação da comunidade escolar no processo decisório. (p. 116)

Em consonância com Castro e França (2007), neste estudo, adotamos o conceito de que descentralizar é dar autonomia a órgãos públicos, administrativos, tornando-os desvinculados do poder central. A autonomia da escola é um princípio adotado na gestão da escola pública como mecanismo de aprimoramento de sua qualidade e de sua adaptação ao meio social na qual está inserida, viabilizando, assim, melhor atendimento às demandas da comunidade. No entanto, no que concerne à gestão dos programas voltados ao caráter suplementar do ensino, administrados pelo Fundo Nacional de Desenvolvimento da Educação em parceria com a Secretaria de Educação Básica, como o Programa Nacional Biblioteca da Escola, objeto deste estudo, a descentralização das ações e a autonomia da gestão, quer seja federativa, municipal ou escolar, pode gerar dificuldades para o atendimento de metas.

Implantar políticas depende de um conjunto de fatores que inclui desde a forma de execução de atividades, a clareza com que metas e objetivos são fixados, a consistência com que são comunicados, a relação entre atividades que envolvem auxílios técnicos e de informação, as condições políticas, econômicas e sociais até o perfil dos executores. 


\section{pro.posições}

\section{Os caminhos percorridos}

Entendemos que uma efetiva política de formação de leitores, para ser implementada, precisa ser acompanhada e avaliada para garantir que não haja esvaziamento da ação, assegurando que a formação de leitores na Educação Infantil, no nosso caso, de fato, aconteça.

Em decorrência dessa perspectiva, consideramos a seguinte questão: quais os fatores que determinam o processo de implementação da política pública de fomento à leitura, por meio do PNBE, na Rede Municipal de Ensino de Natal na Educação Infantil?

Este artigo é um recorte de uma pesquisa, de abordagem quanti-qualitativa avaliativa, sobre O Programa Nacional Biblioteca da Escola - PNBE na Educação Infantil de Natal-RN. Como etapa inicial, fizemos o levantamento dos documentos em forma de Decretos, Leis e Diretrizes que norteiam, regulam o Programa Nacional Biblioteca da Escola - PNBE, por meio dos sites do Ministério da Educação - MEC, que prestam conta da implementação e da distribuição dos livros do programa às escolas públicas de todo o País.

$\mathrm{Na}$ pesquisa de campo, adotamos como instrumentos: entrevista semiestruturada; diário de campo; questionário; observação in loco. Entrevistamos 10 profissionais técnicos e assessores envolvidos no PNBE, sendo 02 em Brasília e 08 na Secretaria Municipal de Educação de Natal-RN; 20 profissionais que atuam diretamente em escolas, sendo 08 coordenadores, 08 gestores escolares e 04 professores, totalizando 30 atores informantes. Os profissionais para a entrevista foram selecionados tendo em vista posições-chave que ocupam na cadeia de implementação da política do PNBE. Do total de 69 unidades de ensino de Educação Infantil de Natal, visitamos e observamos, in loco, 21 Centros Municipais de Educação Infantil - CMEIs da cidade (30\% do total), contemplados com os acervos do PNBE em suas três edições, 2008-2010-2012, para a Educação Infantil. Nessas visitas, foram observados os espaços de leitura, o Projeto Político-Pedagógico das unidades de ensino que norteiam as concepções de leitura dos CMEIs, as práticas pedagógicas dos professores destinadas às crianças, a presença ou ausência do acervo, o seu estado de conservação e armazenamento, e a acessibilidade das crianças e dos professores ao material do PNBE.

Destacamos, neste artigo, algumas vozes de gestores implicados na implementação do PNBE, para entendermos aspectos da distribuição e da utilização do acervo do programa que 


\section{pro.posições}

chega às unidades de Educação Infantil da cidade de Natal-RN. No relato dos depoimentos, adotamos nomes de mitos gregos para preservar a identidade dos informantes.

\section{O PNBE: da gestão ao leitor na Educação Infantil}

O PNBE foi instituído por meio da Portaria Ministerial no 584, de 28 de abril de 1997, tendo como objetivo assegurar o acesso de alunos e professores à cultura, à formação e aos conhecimentos socialmente produzidos ao longo da história da humanidade; isto é, incentivar a prática da leitura nas escolas públicas de todo o Brasil por meio da distribuição de livros de diferentes gêneros textuais (Pereira, 2009).

Os títulos são selecionados e adquiridos por meio de edital público, de acordo com critérios de qualidade literária do texto, adequação temática e projeto gráfico. Além disso, são distribuídas coleções destinadas à formação permanente do professor em todas as áreas do conhecimento (Brasil, 2009).

O PNBE integra as ações "Por Uma Política de Formação de Leitores" desenvolvidas pelo Ministério da Educação, a partir de três eixos norteadores: retomar a biblioteca escolar como foco de ação; distribuir acervos de uso coletivo voltados para a ampliação das bibliotecas e dos espaços de leitura; e universalizar as escolas da educação básica. $\mathrm{Na}$ perspectiva do PNBE, é indiscutível a importância dos livros, assim como a presença de bibliotecas em escolas, sendo elas de Educação Infantil ou não.

Diante desse quadro, este artigo chama atenção para a necessidade de conhecermos e avaliarmos as ações públicas de gestão da política de formação de leitor no âmbito das instituições de Educação Infantil, "já que do ponto de vista de seu papel, a avaliação detecta eventuais falhas e afere os méritos dos programas... . Nesse sentido, sua tarefa é formativa, permitindo a correção ou confirmação de rumos" (Faria, 2009, p. 41).

Sabemos que a instituição escolar é um ambiente de relações humanas e sociais e age com interatividade para alcançar um mesmo objetivo educacional. Contudo, sua forma de organização gerencial, apesar de ter sido importada da iniciativa privada, é diferenciada de uma administração de empresa, porque ela está voltada intencionalmente para a formação humana, e, assim, sua dinâmica engloba características administrativas relacionadas ao fazer pedagógico, 


\section{pro.posıções}

cujas ações buscam a eficiência do processo ensino-aprendizagem, redução e controle nos gastos dos serviços públicos, qualidade e maior autonomia às agências e aos departamentos.

A ação gestora é de fundamental importância para o desenvolvimento organizacional de todas as instâncias da política pública. Ao gestor cabe ser interativo e construir relações internas e externas de comunicação, pois essa é sua principal ferramenta para elucidar e levar o entendimento comum à organização dos setores. O gestor deve transformar informação em conhecimento e saber usá-lo em prol da coletividade. No momento em que a gestão consegue visualizar e mostrar a cada membro da equipe que ele faz parte do todo, podemos dizer que a comunicação e o trabalho se tornam eficazes. Essa é uma estratégia bastante presente no âmbito das políticas públicas, que é o empoderamento. Segundo Castro e França (2007), "esse conceito vem associado à descentralização política, na medida em que envolve a transferência de poder decisório a grupos ou indivíduos previamente sub-representados ou à criação de unidades administrativas relativamente independentes" (p. 134). Esse conceito de empoderamento, entretanto, pode ser contestado, na dinâmica de implementação: a transferência de responsabilidades nem sempre dá resultados, conforme revela a fala de um de nossos atores, ao responder sobre a responsabilidade de acompanhamento do PNBE, no Departamento de Educação Infantil de Natal:

Então, o Departamento não tem uma representante nesse programa. Eu faço parte de uma comissão que trata das questões de leitura na rede, mas não sou a responsável pelo programa até porque o programa não chegou ao departamento, e sim, para o Ensino Fundamental. O MEC não manda nenbuma orientação para a Secretaria, quando a gente sabe já é no assessoramento da escola. (Jocasta, 2014)

A assessora transfere responsabilidade de seu Departamento de Educação Infantil para o Departamento de Ensino Fundamental, quando ela própria faz parte de uma comissão responsável por "questões de leitura no município", portanto, a instância mais ampla na gestão da leitura. Em decorrência, essa profissional e seus pares têm o poder de encaminhar a formação de leitura dos professores que atuam nos Centros Municipais de Educação Infantil. Entretanto, assinala, com razão, que o próprio MEC excluiu seu setor de participar do PNBE, visto que a comunicação do programa se dá diretamente com a escola e, com esse argumento, Jocasta parece entender que não há o que fazer. A voz de Jocasta aponta para a falta de comunicação entre os entes federados. O MEC não se comunica com a Secretaria Municipal de Educação de Natal e essa não mantém seus departamentos articulados. Portanto, os profissionais que atuam nos diferentes departamentos da gestão municipal não dialogam entre 


\section{pro.posições}

si, nem com a escola. Assim, a fala de Jocasta torna visível a inocuidade do empoderamento pretendido pela política pública. Nessa lógica, o PNBE não consegue potencializar a formação de leitores da Educação Infantil, pois os responsáveis pela formação de professores em leitura o desconhecem e, em decorrência, não oferecem formação aos professores para utilizar os livros que chegam às escolas. Sabemos que, em algumas escolas, alguns gestores fazem algum aproveitamento desses livros, mas são casos pontuais, que não vislumbram a meta pretendida pelo programa.

Assim, a descentralização das políticas públicas de leitura no PNBE se configura como uma fragilidade do sistema de ensino da cidade de Natal, visto que seus atores, seja na gestão do órgão central, seja na gestão escolar, ou mesmo os professores que atuam em salas de aula da Educação Infantil, desconhecem o programa, seus objetivos e metas, conforme o recorte das falas daqueles que ocupam cargos de gestão e são responsáveis pelo processo de promoção da leitura.

Ao serem perguntados se conheciam o Programa Nacional Biblioteca da Escola, os atores que ocupam os cargos de gestor municipal, gestor escolar e assessor pedagógico da SME, assim se manifestaram:

Cassandra: Olhe, o programa do PNBE é um programa que dialoga diretamente com a escola, não é? Todos os kits são enviados para a escola. Quando chega nas escolas, a Secretaria tem o conbecimento porque chegou, mas alguns kits não vêm para Secretaria de Educação, eles vêm direto para as escolas... O MEC adentra as escolas e nós, como Secretaria e técnicos, precisamos tomar conhecimento de todas essas ações, muitas vezeses o próprio Ministério da Educação não envia para a Secretaria. Então, isso dificulta o trabalho porque os assessores não têm conhecimento dos acervos. Quando alguns técnicos nossos foram professores, que conbecem o processo de trabalho, porque tiveram acesso a esse material, no caso aqui, como estamos tratando de livros, então eles têm acesso a esses livros, eles fazem esse diálogo, porque já conbecem o programa, vamos dizer assim, vivenciaram os livros na base, lá, lá das escolas, dos CMEIs, eles farem esse diálogo e, aí, fortalecem as formações dos departamentos e o próprio acompanhamento, o desenvolvimento dos projetos, porque eles têm o conhecimento disso que está lá. Então, o MEC peca em alguns momentos por não enviar para as equipes das Secretarias. (Cassandra, 2013)

Hércules: Não, nunca ouvi falar desse projeto, não. Depois que eu cheguei na gestão e depois Perséfones, aqui desde 2008, nós nunca vimos falar nisso, não. Em 2009, ela, ela... en recebi algumas caixas com uns livros aqui. Acho que foi o Governo Federal quem enviou e agora que você tá falando, eu me lembro que tinha um selo, mas o selo rasgou... nunca veio assim um livro explicativo... uma formação... nunca existiu uma orientação formalmente para a gente usufruir da melhor maneira esse material. Desde que estou aqui só vi chegar uma vez... chegou, mas não tinha nada dizendo: - olhe aqui, esses livros fazem parte do Programa Nacional Biblioteca da Escola, vocês vão usar para que a leitura se estenda. Não, nunca veio com isso, não... se... houve uma falta de comunicação, se foi nossa a falha, mas nunca veio nada falando sobre esse projeto e nem como ele deve atuar na escola. Eu sei que existe o programa, mas aqui não chegon da forma que ele deve ser usado, não. Não há nada de forma esclarecedora para gente. (Hércules, 2013) 


\section{pro.posições}

Jocasta: Eu vou responder sobre o que sei. O que sei, sei; o que não sei, não sei. Nesse departamento não existe um responsável pelo PNBE. O PNBE, os livros vêm direto para as escolas e a gente já sabe assim, esporadicamente, porque... olhe, chegou uma caixa do MEC, tá... para nós não vem, porque é direto na escola e quando a gente sabe, é assim sem detalbe. Nós, hoje, estamos com uma formação em linguagem oral e escrita e quando a gente vai fazer nesse âmbito da discussão dos materiais que têm chegado, aí uma comenta, outra comenta, ou então nos nossos assessoramentos, elas dizem: - ah, hoje eu recebi uma caixa do MEC e diz, nós estamos usando isso assim, e nós perguntamos se receberam alguma orientação para usar o material e elas dizem, não. Então, sabemos assim dessa forma. Eu conbeço o que é o PNBE, Plano Nacional Biblioteca da Escola, mas não sei a essência. Nunca chegou para a gente aqui, enquanto departamento, o que é, com que frequência isso acontece e quais são as unidades de Educação Infantil que são contempladas. Nós tomamos conhecimento quando chega, informada via a própria instituição e assim, por acaso, quando estamos em formação, estamos em assessoramento... a própria instituição nem sabe a origem desse material, se ele é ou não desse programa, e não vem nenbuma formação para isso, nem para a escola nem para Secretaria, nem via direto instituição de Educação Infantil. (Jocasta, 2014)

As falas dos entrevistados revelam que os próprios atores que trabalham diretamente com a leitura não fazem um exercício profícuo do ato de ler, pois, como diz Silva (1992), a leitura é o instrumento necessário à compreensão do material escrito e também pode ser vista como uma fonte de conhecimentos. $\mathrm{O}$ argumento dos gestores de que não são informados sobre o Programa se fragiliza, quando descobrimos que juntamente com as caixas que compõem cada acervo, o Ministério da Educação remete uma carta informativa explicando do que trata o Programa Nacional Biblioteca da Escola, com o endereço do site e números dos telefones que tratam da distribuição e outras informações sobre o PNBE, como os nomes das obras que compõem o referido acervo. Entretanto, entendemos que, de fato, o MEC poderia ter ação mais efetiva na divulgação do programa, estabelecendo vínculos mais diretos com todos os responsáveis por sua implementação. A carta que acompanha as caixas com os acervos, até o ano de 2012, limite deste estudo, é um documento impessoal e se perde nos meandros das inúmeras atribuições dos gestores e dos funcionários. É preciso alguém que entenda a importância do Programa para abrir as caixas, ler a carta e abrir os livros para as crianças.

A partir do site do Ministério da Educação, encontramos materiais que favorecem, explicam e auxiliam os gestores e os professores a utilizar o acervo do PNBE, tais como o “Guia do Livronauta" (PNBE, 1998); "História e Histórias” (PNBE, 1999); além de outras publicações voltadas para a formação de leitores, como a Revista Leituras, o kit "Por uma Política de Formação de Leitores" e o volume 20, "Literatura Infantil - Coleção Explorando o Ensino". Todo esse material de consulta discute os objetivos do programa e dá orientações políticas e pedagógicas sobre a distribuição, circulação e leitura dos livros de literatura para a infância. De todos esses materiais instrucionais, o "Catálogo Literatura na Infância: imagens e 


\section{pro.posıções}

palavras" (PNBE 2008) e o "Guia PNBE na Escola: Literatura fora da caixa” (2014) se destinam à Educação Infantil, sendo que o Guia (2014) está fora do limite temporal desta investigação.

A despeito dessas informações sobre o programa, o mecanismo de comunicação por carta e por guia parece não surtir o efeito esperado. A propósito, reproduzimos a fala de um gestor:

Aqui nós não temos tempo para esse tipo de informação, porque somos 'mil e uma utilidades', fazemos muitas prestaçôs de conta: é merenda, PDE, PDDE, tomada de preço, ponto de professores e até Conselho Tutelar.

... Eu conheço o PNBE, mas não tivemos tempo para ler sobre ele, não. Não sei exatamente a sua essência. (Prometeu, 2014)

O depoimento de Prometeu revela outra fragilidade da descentralização: atribuem-se aos funcionários inúmeras tarefas e com isso, compromete-se o objetivo pedagógico de programas como o PNBE. Em tempos de políticas de descentralização, a escola absorve uma gama de responsabilidades para serem executadas pela Equipe Gestora, com a participação de todos os segmentos da escola:

Esse modelo está ancorado na transferência de responsabilidades e atribuições aos estados, províncias e/ou municípios; na delegação (para as escolas) de responsabilidade de atividades que tradicionalmente seriam desenvolvidas pelo âmbito central; e na inclusão da comunidade local na gestão e no financiamento das unidades escolares. (Castro \& França, 2007, p. 133)

Concordamos com a autora, quando afirma que essa diretriz governamental prevê autonomia e participação da comunidade escolar, em especial, no gerenciamento dos recursos descentralizados. Porém, enxergamos nisso duas problemáticas: a primeira diz respeito ao excesso de ações administrativas e financeiras demandadas aos profissionais da escola centralizadas na gestão; a outra é a falta de responsabilização em assumir, por exemplo, uma política de leitura dentro de uma rede de ensino, como o PNBE, visto que a transferência de responsabilidade é difusa: chega ao gestor da escola uma caixa com livros e uma carta explicativa. Será isso suficiente para assegurar o desenvolvimento adequado do programa? É importante ressaltar que todas as escolas públicas do País recebem o acervo do PNBE, quer o gestor o tenha solicitado ou não.

Aspecto relevante da implementação da política é a formação de professores para atuar como formadores de leitores. Mesmo desconhecendo o acervo do PNBE, a Secretaria 


\section{pro.posıções}

Municipal de Educação é responsável pela formação permanente de seus profissionais. $\mathrm{O}$ Gráfico I mostra que 88\% dos atores envolvidos não participaram de ações de formação em leitura nos últimos três anos, promovidas pela Secretaria Municipal de Educação e pela iniciativa privada, como o Programa Prazer em ler, Trilhas e outros: iniciativas que acontecem fora do planejamento pedagógico dos Centros Municipais de Educação Infantil. Esse dado demonstra a desarticulação dos CMEIs com a própria Secretaria Municipal.

Gráfico 1 - Formação continuada em leitura fora dos CMEIs

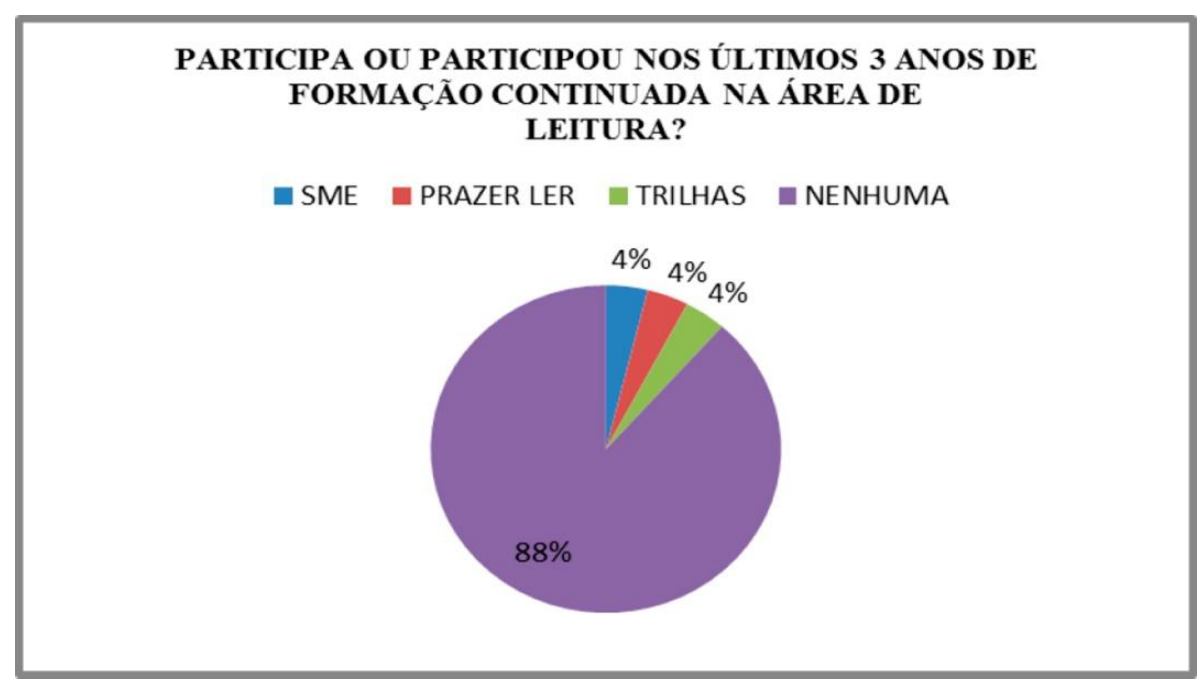

Fonte: Elaborado para fins desta pesquisa, 2014.

Referência: Pesquisa realizada nos Centros de Educação Infantil em Natal/RN, 2013-2014.

O Gráfico 1 apresenta uma situação problemática para 88\% dos educadores que, durante o intervalo de 2010 a 2013, não participaram de nenhuma formação em leitura. Assim como a criança, o professor também deve ter formação em leitura. O professor leitor deve desenvolver com regularidade e competência práticas de leitura, para delas usufruir como um bem que lhe traz benefícios pessoais e favorece o exercício de sua profissão. Mas, como ser um mediador de leitura sem formação? Como formar um leitor na escola? Como ser mediador sem conhecer repertório de obras relevantes para suas crianças?

Alicerçados nos estudos específicos que tratam das políticas públicas, entendemos que toda política pública deve ser monitorada e avaliada. É necessário também verificar se a conclusão das atividades coincide com o programado, detectar deficiências, obstáculos e/ou 


\section{pro.posıções}

necessidades de ajustes da execução. Entretanto, é importante ressaltar que ações de acompanhamento sistemático de uma política não devem estar restritas à compatibilidade entre valores programados e executados, visto que "os processos de monitoramento e avaliação são complementares, mas a avaliação vai além, na medida em que verifica se o plano originalmente traçado está efetivamente alcançando as transformações que pretendia, subsidiando a definição de políticas públicas” (Santos, 2012, p. 7).

É pelo fato de não convocar seus colaboradores do circuito da formação leitora que a descentralização do programa compromete a chegada do livro às pequenas crianças. No nível de Educação Infantil, o que interessa na relação entre o professor mediador de leitura e a criança é o entusiasmo pelo que se está lendo, o desejo de compartilhar experiências com quem convive com a leitura e nos lugares onde se convive, apresentando à criança diversidade de textos, despertando-lhe o interesse pelo manuseio de livros que devem permanecer visíveis, dispostos e acessíveis por todos os lugares em que a criança transita. Nesse caso, a biblioteca é o local adequado à realização do contato lúdico com o livro onde o acervo se oferece.

Por essa razão, foi observada a presença da biblioteca nas escolas de Educação Infantil. Conforme entendemos, a biblioteca é o lugar para a entrada dos livros e da leitura, como disse Lobato, em A Reforma da Naturez̧a (2010). Não há como pensar a biblioteca sem idealizar um espaço físico com a participação de profissionais que conhecem seu papel na formação das crianças. É nela que o acervo do PNBE deve encontrar sua melhor acolhida.

A propósito de espaços de leitura, consultamos o Questionário do Comitê Gestor do Plano Municipal de Leitura Literária na Escola, o PMLLE, que, no ano de 2013, colheu informações sobre a Rede Municipal de Ensino de Natal, no que se refere à leitura. Apesar das leis que instituem a criação de biblioteca em todas as escolas brasileiras, de acordo com os dados coletados, poucos Centros de Educação Infantil afirmam possuir biblioteca escolar, conforme mostra o Gráfico 2: 


\section{pro.posıções}

Gráfico 2 - Espaços de leitura nos CMEIs, segundo informação dos gestores

\section{EXISTE ESPAÇO DE LEITURA NO CMEI? QUAL?}

$\because$ CANTINHO $\square$ BIBLIOTECA $\square$ SALA DE LEITURA $\square$ NÃO EXISTE

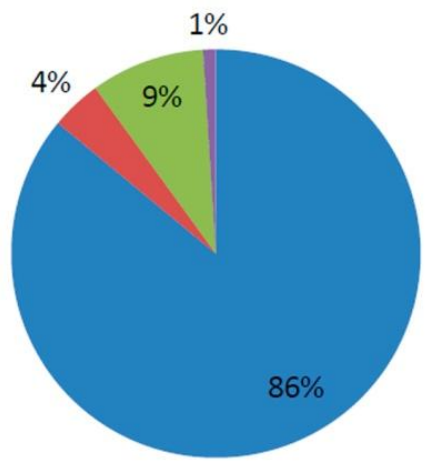

Fonte: Elaborado para fins desta pesquisa, 2013.

Referência: Questionário Comitê Gestor PMLLE.

A pesquisa de campo nos revelou, porém, que poucas escolas possuem sala de leitura e que algumas delas são assim denominadas sem a devida condição, uma vez que se trata de uma brinquedoteca ou uma sala de multiuso, ou uma sala de apoio pedagógico, dividindo o espaço com o professor em planejamento e com outros materiais.

Embora os gestores tenham informado a existência de biblioteca escolar, de fato, na visita in loco, constatamos que nenhuma das 69 unidades de Educação Infantil de Natal-RN apresenta esse espaço. Ou os gestores não sabem o que é uma biblioteca escolar ou responderam de forma equivocada.

É verdade que a ausência da biblioteca pode não se constituir em entrave ao uso do acervo do PNBE ou à falta de prática pedagógica voltada para a promoção da leitura na Educação Infantil. Entretanto, lembramos que um eixo do programa é, justamente, a biblioteca da escola, que está no próprio nome do PNBE - Programa Nacional Biblioteca da Escola. De maneira predominante, observamos que caixas, cestos, varais, carrinhos de supermercado com alguns livros são alocados nas salas de aula e são denominados de Cantinho da Leitura. Essa é uma alternativa de oferta às crianças do acesso ao livro, mas jamais pode ser entendida como substituição à biblioteca. A existência da biblioteca é muito importante para tornar significativo o contato das crianças pequenas com a pesquisa, a cultura, 


\section{pro.posições}

os livros e com outros materiais de informação, além de permitir-lhes a exploração do conhecimento e o trânsito entre os espaços que congregam, simultaneamente, a cultura, a literatura e o saber. Ensino e biblioteca são instrumentos essenciais para a formação integral do estudante: "ensino e biblioteca não se excluem. Completam-se. Uma escola sem biblioteca é um instrumento imperfeito" (Silva, 2003, p. 67).

Mesmo sendo consenso, entre a maioria dos entrevistados que ocupa os cargos de gestão, que a existência de uma biblioteca na Instituição de Educação Infantil é de fundamental importância para se criar o gosto pela leitura e a familiaridade com o espaço de pesquisa e do saber, encontramos, ainda, a voz de uma gestora que desconhece o papel da biblioteca nessa etapa da educação. Destacamos sua fala pelo poder que detém no circuito de implementação das políticas públicas. Ao ser perguntada sobre o fato de que nenhum Centro de Educação Infantil de Natal possui biblioteca adequada e sobre o cumprimento da Lei 12.244, que dispõe sobre a universalização das bibliotecas nas instituições de ensino do país, essa gestora afirmou:

Cassandra: Olhe, biblioteca não tem. Mas francamente, você acha que deve ter biblioteca para criança tão pequena? O que uma criança de pré-escola e berçário faria numa biblioteca? Nós estamos lutando para cumprir a lei, mas será que podemos e devemos fazer biblioteca na Educação Infantil? Ainda não sei. (Cassandra, 2014)

Com relação ao que a criança pequena e o bebê poderiam fazer na biblioteca, Parreiras (2012) esclarece que

para as crianças pequenas e os bebês, a biblioteca será espaço inaugural do contato com as emoções e as sensações. Os bebês precisam tocar nos livros, cheirar, chupar, morder. Sua pele vai se aproximar desse objeto tão atraente em rodas de crianças monitorada pelos adultos. Nessa etapa do desenvolvimento, o mais importante é o toque e toda a estimulação dos sentidos. Então, é necessário criar um ambiente tranquilo, para cantar para os bebês, para ler contos, para declamar poemas. (p. 191)

Em outro ponto da cidade, mesmo sem ter ouvido a resposta de Cassandra, Pandora responde, do chão da escola onde é coordenadora,

Pandora: Pelo amor de Deus, a gente não diz. que é desde pequeno que a criança tem que ser incentivada e estimulada à leitura? Se é desde pequena, o CMEI tem que nascer já com sua biblioteca, não é não? Já tem que nascer! É uma pena que no Brasil nossas escolas, né, sejam os puxadinhos. Puxa uma sala, depois puxa não sei o quê, puxa um refeitório e depois que puxa tudo, puxa um cantinho para ser uma biblioteca. Uma biblioteca, né? ... Nossa escola era pra ter tudo e, principalmente, uma biblioteca. Então as coisas no Brasil são 


\section{pro.posições}

feitas às avessas. É o país do contrário, assim meio as coisas em desequilíbrio. Como é que se cria uma escola com salas de aula sem biblioteca? Pensar a escola nesse país é como se não fosse importante, mas a escola é o lugar mais importante de um país, por isso tem que ter biblioteca, é ali que estão os cérebros, é dali que parte toda uma cultura... Mas ainda espero que nos CMEIs, pelo amor de Deus, venha com a biblioteca e que as pessoas, deem importância à biblioteca na escola como dão ao refeitório das crianças. (Pandora, 2014)

Ao igualar o status da biblioteca na escola ao do refeitório, Pandora nos lembra da imagem do livro pão de Lobato (Lobato, 2010). A fala de Cassandra revela a falta de compreensão que se tem do uso da biblioteca por crianças pequenas, assim como o desconhecimento de como se organiza uma biblioteca para as crianças nesse nível de educação. Para Cassandra, a criança da Educação Infantil não teria o que fazer na biblioteca, pois, sob a sua ótica, desconsiderando as principais teorias que fundamentam a educação da criança de zero a cinco anos, todos os sujeitos que frequentam uma biblioteca devem possuir as mesmas habilidades cognitivas da fase adulta.

Já na fala da coordenadora, percebemos que há entendimento a respeito da necessidade de se formar a criança leitora desde a Educação Infantil. Pandora entende a biblioteca escolar como um lugar de aprendizagens, um espaço planejado adequadamente e organizado para esse fim, e faz em um discurso carregado de emoção e de severas críticas ao fato de não se ter biblioteca nas escolas de Educação Infantil, aos arranjos feitos para se disponibilizar o acervo para as crianças e à falta de cumprimento da lei no Brasil e no município de Natal.

A biblioteca da qual falamos, neste estudo, é a biblioteca infantil, espaço lúdico por excelência que abriga várias atividades do brincar com o intuito de criar e desenvolver o gosto pela leitura, adquirir conhecimento e desenvolver o comportamento leitor dentro de um espaço constituído na sociedade como centro de cultura. A criança pequena não frequenta a biblioteca escolar com a mesma finalidade das crianças maiores ou dos adultos. A inserção das bibliotecas nas escolas de Educação Infantil tem a finalidade de desenvolver nas crianças uma atitude positiva, confortável, lúdica com relação ao espaço, onde poderão aprender a abrir os livros e descobrir o que eles guardam em seu silêncio. 


\section{pro.posições}

\section{Para onde vamos?}

A implementação de uma política de formação de leitores, a distribuição de livros feita pelo PNBE e a presença de livros de qualidade nas escolas não garantem, à luz das ideias lobatianas, que "um país se faz com homens e livros". Em virtude do modelo de gerenciamento pautado pela descentralização das ações relativas ao PNBE, os livros chegam em caixas diretamente para os Centros de Educação Infantil de Natal, sem o conhecimento de setores da Secretaria e, em decorrência, os resultados da pesquisa apontam para a invisibilidade do programa, visto que não existem atores responsáveis pelo gerenciamento do PNBE e, tampouco, pela efetiva implementação da política de fomento à leitura e de democratização do livro de literatura para as crianças desse nível de educação.

Sabemos que, ao longo da existência de qualquer política pública, surgem as necessidades de ajustes, porque, no ciclo das políticas públicas, após as etapas de implementação, sucedem-se as de avaliação e de extinção. A avaliação é necessária para que novos rumos sejam tomados em busca do alcance dos objetivos da promoção da leitura. A extinção só ocorre quando as metas foram alcançadas. Compreendemos que a constituição de uma política de leitura eficaz tem como premissa a interlocução dos entes federativos em nível federal, estadual e municipal. Nessa perspectiva, faz-se necessária a criação de um canal de comunicação com o objetivo de fortalecer o diálogo com o Ministério da Educação por meio do acompanhamento sistemático dos seus programas e ações destinados à melhoria da qualidade da educação pública, com vistas a reparar a invisibilidade do Programa Nacional Biblioteca da Escola e garantir melhorias na qualidade do gerenciamento do PNBE, nas três esferas do governo e, por conseguinte, a efetiva implantação da política de fomento à leitura e a democratização do livro para crianças e professores desse nível de ensino.

De acordo com os nossos estudos, compreendemos que a literatura é educativa e imprescindível para a formação leitora. Trabalhar a promoção da leitura, inevitavelmente passa pela formação do leitor com uma prática pedagógica e uma teoria sólida para iniciar a criança no mundo das palavras, da literatura e da imaginação. Para tanto, urge uma ação que abra os livros que chegam às escolas por meio do financiamento do Governo Federal. O próprio MEC deve aperfeiçoar seus mecanismos de comunicação com os outros atores envolvidos no circuito da implementação do PNBE. A ausência de acompanhamento do acervo desde sua aquisição até a chegada às mãos das crianças, apoiada por um modelo de descentralização, não 


\section{pro.posıções}

pode continuar a ser um trajeto de transferência de responsabilidades ad infinitum, visto que a existência do Programa é uma conquista social do direito à leitura, que deve ser assegurado com responsabilidade.

O conhecimento do Programa Nacional Biblioteca da Escola - PNBE, por todos os envolvidos no processo, é um aspecto propulsor para que se disseminem atividades de leitura coerentes com a proposta desse programa e, mais ainda, com uma política de formação de leitores que se propõe a atingir os estudantes de todas as escolas brasileiras.

Sendo assim, todos os gestores da Secretaria de Educação e os escolares precisam ter conhecimento do programa em geral, dos aspectos específicos e das diretrizes que norteiam a sua meta: por uma política de formação de leitores. Precisamos de gestores que sejam qualificados sobre o programa, que se debrucem sobre o material orientador, que divulguem o PNBE e levem a sério a política pública de leitura que, no ano de 2015, estava na quarta edição para Educação Infantil, foco deste estudo, e ainda permanece invisível na Rede Municipal de Ensino de Natal.

Compreendemos, por conseguinte, que a presença de livros na escola não é suficiente para a implementação de uma política de formação do leitor. Para nós, a mediação de leitura é a questão central para manter forte a política do livro e da leitura. Já que desejamos formar leitores iniciados na escola, é preciso capacitar o professor, sujeito facilitador do encontro entre o leitor e o livro e, envolver, responsavelmente, todas as instâncias do sistema escolar para que as metas do programa sejam atingidas. Na mesma medida que investe em livros, o governo deve investir na capacitação de gestores e de professores, no incremento e no aparelhamento das estruturas físicas promotoras da leitura, pois, sem mediação segura, sem agentes bem formados e sem estruturas adequadas, dentre as quais está a biblioteca, a ação política sobre a leitura se pulveriza.

Nosso intuito é que as análises desta pesquisa possam, de alguma forma, contribuir para o gerenciamento de uma relação mais produtiva entre a distribuição de obras por intermédio do Programa Nacional Biblioteca da Escola - PNBE e a formação de leitores na Educação Infantil de Natal-RN.

Os livros não foram feitos para ficar fechados, restritos ao silêncio. É preciso que todos se mobilizem para que o silêncio se rompa e as crianças abram o livro. 


\section{pro.posıções}

ISSN 1980-6248

\section{Referências Bibliográficas}

Brasil (2009). Por uma política de formação de leitores. Brasília: Ministério da Educação, Secretaria de Educação Básica.

Candido, A. (2012). O direito à literatura. In A. Lima et al., O direito à literatura (pp.17-40). Recife: Editora Universitária da UFPE.

Castro, A. M. D. A., \& França, M. (2007). Gerencialismo e educação: estratégias de controle e regulação da gestão escolar. In A. Cabral Neto, Pontos e contrapontos da política educacional: uma leitura contextualizada de iniciativas governamentais (pp.115-144). Brasília: Líber Livro.

Castro, A. M. D. A., \& França, M. (2012). Politica educacional: contextos e perspectivas da educação brasileira. Brasília: Liber Livro.

Faria, M. (2009). Como usar a literatura infantil na sala de aula. São Paulo: Contexto.

Lobato, M. (2010). A reforma da natureza (2a ed.). São Paulo: Globo. (Obra original publicada em 1941)

Melo Neto, J. C. (1994). Para a Feira do Livro. In J. C. de Melo Neto, Obra completa (vol. único, p. 367). Rio de Janeiro: Nova Aguilar.

Parreiras, N. (2012). Do ventre ao colo, do som à literatura. Belo Horizonte: RHJ.

Pereira, A. K. (2009). Biblioteca na escola (A. K. Pereira, elaboração). Brasília: Ministério da Educação, Secretaria de Educação Básica.

Rua, M. G. (2009). Políticas públicas. Florianópolis: Departamento de Ciências da Administração, UFSC.

Santos, P. S. M. B. (2012). Guia prático da política educacional no Brasil. Ações, planos, programas e impactos. São Paulo: Cengage Learning.

Secchi, L. (2010). Políticas públicas: conceitos, esquemas de análise, casos práticos. São Paulo: Cengage Learning.

Silva, E. T. (1992). O ato de ler: fundamentos psicológicos para uma nova Pedagogia da Leitura (6a ed.). São Paulo: Cortez. 


\section{pro.posıções}

Silva, S. F. (2015). O Programa Nacional Biblioteca da Escola - PNBE: da gestão ao leitor na Educação infantil de Natal (284 pp.). Dissertação de Mestrado. Universidade Federal do Rio Grande do Norte.

Silva, W. C. (2003). Miséria da biblioteca escolar (3a ed.). São Paulo: Cortez.

Tuttle, C. G., \& Paquette, P. (1993). Invente jogos para brincar com seus filhos. (B. Lambert, trad.). São Paulo: Loyola. (Obra original publicada em 1991)

Submetido à avaliação em 28 de setembro de 2015; aceito para publicação em 28 de julbo de 2016. 
(em branco) 